\title{
The Effect of Formal New Product Development on the Project Goals: A case from Malaysian Low-Volume Car Producer
}

\author{
B. Hambali' ${ }^{1}$, T. Mokudai ${ }^{2}$, A. Hambali ${ }^{3}$, and M.I. Ramli $\square$. \\ $1 \square$ Fakulti Teknologi Kejuruteraan Mekanikal dan Pembuatan, Universiti Teknikal Malaysia Melaka, Malaysia \\ Hang Tuah Jaya, 76100 Durian Tunggal, \\ Melaka, Malaysia.hambaliboejang@utem.edu.my, and irman@utem.edu.my \\ ${ }^{2}$ Faculty of Economics, Kyushu University, 744 Motooka Nishi-ku Fukuoka 819-0395, Japan. \\ mokudai.takefumi.076@m.kyushu-u.ac.jp \\ ${ }^{3}$ Fakulti Kejuruteraan Pembuatan, Universiti Teknikal Malaysia Melaka, Hang Tuah Jaya, 76100 Durian \\ Tunggal, Melaka, Malaysia. hambali@utem.edu.my
}

\begin{abstract}
This research explores and identifies how formal new product development of a small-sized (low-volume) car manufacturer in Malaysia affects the development project goals. It explains the approach used by this producer to overcome the project characteristics as well. To understand the research topic, related literature was reviewed and information was gathered to develop the hypotheses and questionnaire. Later, the questionnaire was pre-tested before the interview sessions with relevant respondents from the product development teams. The feedback was used to develop a questionnaire and conduct a survey afterward. A descriptive statistical analysis was done to quantify the perception of the respondents. The results show that the formal process of product development is crucial to overcome the project-characteristics of process complexity, technological uncertainty, and innovation. Development activities of project scope and size, mule car, and prototype testing have positive impacts on both project goals, but not the model fixed. As such, from the overall study, it can be said that formal new product development is important to producers of products and it must be established and organized according to the producer's business conditions.
\end{abstract}

Key words: new product development, model fixed, mule car program, project scope and size, prototype testing, project goals.

\section{INTRODUCTION}

It is common now for manufacturing enterprises to have a specific new product development process that suits their business conditions [1], [2]. From the literature, the importance of a formal new product development process to the automotive industry is obvious, and it has been part of the strategic business practice [3], [4]. Automakers have adopted certain development processes that are appropriately meeting the demand from customers and contemporary technologies. To ensure the optimum development project performance, an NPD process must consider activities within the development phase that able to reduce uncertainties and risks [5],[6]. Thus, planning a well-organized NPD is crucial to manufacturers, and according to Iansiti [7] the effective planning is important, and the ability to manage product development through strong project management strategy enables success to be achieved. Moreover, Nakata and Sivakumar [8] indicated that, although national culture and NPD have a close relationship, it has been largely neglected in the literature. As such, to improve the understanding of a firm-level NPD project performance of a low volume car producer that has constraints in terms of budget, NPD expertise as well as capability, and to present the geographical differences in NPD, this study explores the NPD of a low volume car producer in a late industrialization nation: Malaysia.

A well-organized NPD is normally represented by phases, gateways, and milestones with dedicated development timings. It starts with the planning phase and ends-up with product launching and continues with mass-production [9]. According to Beaume et al. [10] in the automotive industry, innovation management is about the interplay between product development projects and knowledge activities. A specific NPD process is adopted by a manufacturer for several reasons or conditions that are critical, and significantly able to improve the efficiency and effectiveness of the NPD performance. Unger and Eppinger [11] saw the NPD process as to how an organization managing risks and uncertainties, whereas Kahn et al. [12] interpreted the approach as a tool to solve deficiencies in NPD. For this Malaysian car producer, 
B. Hambali et al., International Journal of Emerging Trends in Engineering Research, 8(10), October 2020, 6873 - 6878

some of the development activities within the NPD phases are illustrated in Table 1.

Table 1 Development practices within NPD [9]

\begin{tabular}{|l|l|}
\hline View & $\begin{array}{l}\text { The development activities used to contend } \\
\text { Project Characteristics }\end{array}$ \\
\hline $\begin{array}{l}\text { 1. The formal } \\
\text { product } \\
\text { development } \\
\text { process and } \\
\text { scopes (formal } \\
\text { project planning) }\end{array}$ & $\begin{array}{l}\text { Phase 0: Market and product feasibility, } \\
\text { technology, and concept. } \\
\text { i. Guideline for product scopes and size } \\
\text { (GPS) }\end{array}$ \\
& \multicolumn{1}{c|}{$\begin{array}{c}\text { ii. Mule car program (MCP). } \\
\text { iii. Model-fixed (MF). }\end{array}$} \\
\cline { 2 - 3 } & $\begin{array}{l}\text { Phase 1: Product, Process development, } \\
\text { technology, and concept. } \\
\text { i.F-proto (testing for design validation). }\end{array}$ \\
\cline { 2 - 3 } & $\begin{array}{l}\text { Phase 2: Process validation and product } \\
\text { confirmation } \\
\text { i.P-Proto (testing for process validation). }\end{array}$ \\
\hline
\end{tabular}

As for this Malaysian car producer, the classification of the development project size and scope gives a better picture upfront to the development team. The project size and scope tell how much changes and/or redesign are needed or involved in a particular development project. The nature of NPD projects comes with a high level of product-process uncertainty, and other risks. The degree of the uncertainties and risks is likely to increase when the NPD project requires for new components and modules, or new technology [13]. Wheelwright and Clark [14] classified development projects according to a degree of change in the product and also in the manufacturing process with different degrees of product-process complexity and risks. On the other hand, this also means that project size and scope is based on project characteristics. As such, the guideline is believed to have a significant impact on both the development lead time and cost.

Also, in some cases, mule cars are used for benchmarking, where product from the competitor is dismantled for the development team to do a comparative analysis and know-how acquisition to get a clear picture of a specific technology and assembly processes being used by the competitors to avoid uncertainty and risk. This requires some budget allocation for mule car acquisition, thus, affecting the development cost. As such the perceptions for the mule car program are that it improves the development lead time, but increases the development cost. The mule car program is one of the motivations behind this study.

The model fixed is part of the development activities where the interior design of a developed car is freeze, allowing final decisions to be made. The development team and top management will finalize any design issues related to the interior design of a car being developed. It is a crucial stage where decisions on uncertain issues related to the concept of the developed product are made whether it should be proceeded, abandoned, or put on hold [15]. As such, the model fixed has been considered as development activities that improve the development lead time. However, it is not for the development cost. For this perception, the hypothesis is made as a 'what if' scenario since the low volume car producer has its constraints in NPD, unlike the proven assumptions normally made for the big players in the automotive industry.

Finally, the prototype testing is where the prototype version of components undergoes several tests for design validation and verification purposes. The prototyping or testing activities are done by using the F-prototype (alpha) and P-prototype (beta) at different stages in the NPD. The testing takes place in phase 1 (Product-Process Development, Prototype Build, and Design Validation). The P-prototype refers to a prototype testing of a component made from an actual manufacturing process such as injection molding and dies press at phase 2 (Process Validation and Product Confirmation). The availability of prototypes helps to reduce uncertainties and risks, therefore speed-up the development time [16], [17]. However, the testing where prototypes are designed, built, tested, and analyzed requires certain budget allocation, and this is assumed to have and increment in the development cost, even though, the previous studies proved vice-versa [18], [19]. The more prototypes are used, the more the budget or cost is needed. Thus, the statements of perceptions, for this study are believed to have positive impacts on the development lead time, but negative on the development cost.

All of these four development activities are believed to have positive impacts on the development lead time, but not for the development cost when considering the constraints of the NPD, facing by the low volume car producer particularly for the MCP, MF, and F-proto and P-proto. Also, the perceptions are based on the feedback from the interview and literature, insisting that a formal NPD process helps manufacturers to achieve the development project goals [11], [20].

Most of the project goals are common for many manufacturers of various products. It is closely related to NPD performance. The success and failure of the NPD project can be seen from different perspectives i.e. financial performance, development speed and cost, customer acceptance, and market share at different levels: product and firm-levels. The dimensions can also be seen as internal as well as external goals [21]. For example, Mu [22] suggested that marketing capability is positively associated with NPD performance. According to Fantazy and Salem [23], there is a positive association between performance and NPD flexibility. Moreover, Clark and Fujimoto [24] defined the product development process as being information and knowledge-intensive work. Therefore, the product development process has a major impact on the cost, quality, and timing of the launch of a product [25]. 
B. Hambali et al., International Journal of Emerging Trends in Engineering Research, 8(10), October 2020, 6873 - 6878

\section{METHODOLOGY}

This study adopts the mixed-method research design to answer the research questions. The critical research question is:

1. How does the formal new product development process of the Malaysian car producer affect its project development cost and lead time?

Information was gathered via a systematic research review method by which documents were reviewed across several scholarly databases. From the literature, the questionnaire that represents the research hypotheses was designed and developed. The draft version of the questionnaire was sent off via email to the contact person for pre-testing purposes. Once the feedback was obtained and the questionnaire was fine-tuned, a final survey form was distributed to the development teams of 49 respondents about a month after. The participation in the survey includes a senior manager from the Planning Division and a senior executive from the New Product Introduction Unit, together with two project managers from two different vehicle programs, and the rest is the development team members.

\subsection{The Hypotheses}

The hypotheses of the formal NPD were drawn and developed from the literature and as well as from the interview. From the interview, it is found that the most important project goals for this car producer are the development lead time (LT) and cost (DC). The development practices or variables under investigation are the guideline of project scope and size (GPS), mule car program (MCP), model fixed (MF), and the prototype testing (F-proto and P-proto). The following are the hypotheses generated from both findings: interview and literature, and represented by Figure 1 .

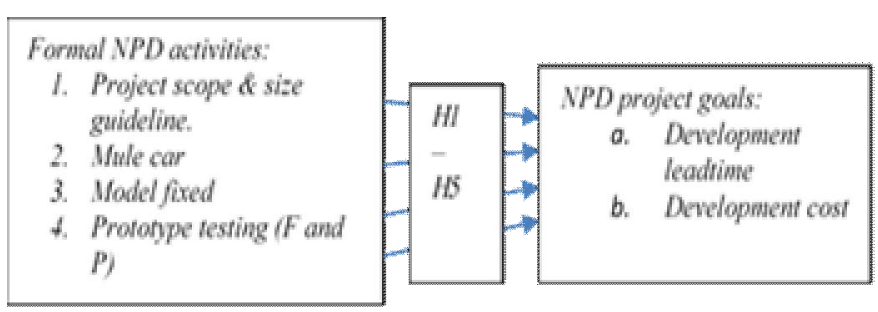

Figure 1 Research hypotheses

H1a: The well-defined guideline for project scope and size (GPS) is positively associated with the development lead time.

H1b: The guideline for project scope and size (GPS) is positively associated with the development cost.

H2a: The mule car program (MCP) is positively associated with the development lead time.

$\mathrm{H} 2 \mathrm{~b}$ : The mule car program (MCP) is negatively associated with the development cost.

H3a: The model fixed (MF) is positively associated with the development lead time
$\mathrm{H} 3 \mathrm{~b}$ : The model fixed (MF) is negatively associated with the development cost.

H4a: The F-prototype testing (F-proto) is positively associated with the development lead time.

H4b: The F-prototype testing (F-proto) is negatively associated with the development cost.

H5a: The P-prototype testing (P-proto) is positively associated with the development lead time.

H5b: The P-prototype testing (P-proto) is negatively associated with the development cost.

The hypotheses were assigned with the capital letter $\mathrm{H}$, a number $(1-5)$, and small letters (a) and (b). the capital letter $\mathrm{H}$ represents the hypotheses of the development activities: the project scope and size, mule car, model fixed, and prototype testing. Meanwhile, the number is designated for each of these development activities, and the small letter (a) and (b) refer to the project goals. Small letter (a) is dedicated to development lead time and (b) is for a development cost. Except for the prototype testing the development activities are divided into $\mathrm{H} 4$ and $\mathrm{H} 5$, representing the F-prototype, and P-prototype relatively. From the results obtained via the interview and literature, all the assumptions or perceptions (H1 - H5) are positively associated with the development lead time. Meaning that these development activities have positive impacts on the project goals i.e. reduces the development lead time. On the other hand, the negatively associated means that the development activities have negative impacts on the project goals i.e. increase the development lead time and cost.

Further, the responses from the participants are tabled and analysed using Excel of Microsoft Office Professional Plus 2016. The non-parametric statistical analysis is the best technique for ordinal and nominal qualitative data [26]. As such, the descriptive analysis was used to assess and examine the ordinal data to see the effects of selected development activities under formal NPD. The perceptions of the constructs were rated using the five-point Likert scale (see Table 2), and from the frequency of the responses, the descriptive statistics were first established.

Table 2 Likert scale of responses

\begin{tabular}{|c|l|l|}
\hline Scale & Likert scale & Symbol \\
\hline 1 & $\begin{array}{l}\text { Strongly } \\
\text { disagree }\end{array}$ & SD \\
\hline 2 & Disagree & D \\
\hline 3 & $\begin{array}{l}\text { Neither } \\
\text { Disagree nor } \\
\text { Agree }\end{array}$ & N \\
\hline 4 & Agree & A \\
\hline 5 & Strongly agree & SA \\
\hline
\end{tabular}

\section{RESULTS AND DISCUSSION}

About $51 \%$ of the respondents gave feedback. The descriptive statistical analysis was made for each of the hypotheses of the 
B. Hambali et al., International Journal of Emerging Trends in Engineering Research, 8(10), October 2020, 6873 - 6878

development practices. The effects of formal NPD on the development project goals are shown in Table 3.

Table 3 The effect of formal NPD on the project goals

\begin{tabular}{|c|c|c|c|c|c|c|c|c|c|c|}
\hline $\begin{array}{l}\text { Hypot } \\
\text { heses }\end{array}$ & $\begin{array}{l}H 1 \\
a\end{array}$ & $\begin{array}{l}H 1 \\
b\end{array}$ & $\begin{array}{l}\mathrm{H} 2 \\
a\end{array}$ & $\begin{array}{l}H 2 \\
b\end{array}$ & $\begin{array}{l}\mathrm{H} 3 \\
\boldsymbol{a}\end{array}$ & $\begin{array}{l}H 3 \\
b\end{array}$ & $\begin{array}{l}\mathrm{H} 4 \\
a\end{array}$ & $\begin{array}{l}H 4 \\
b\end{array}$ & $\begin{array}{l}\text { H5 } \\
a\end{array}$ & $\begin{array}{l}H 5 \\
b\end{array}$ \\
\hline & 4.4 & 4.0 & 3.8 & 2.8 & 4.0 & 2.5 & 4.1 & 2.6 & 3.9 & 2.8 \\
\hline
\end{tabular}

\begin{tabular}{lllllllllll}
\hline $\begin{array}{l}\text { Media } \\
\mathrm{n}\end{array}$ & 5.0 & 4.0 & 4.0 & 3.0 & 4.0 & 2.0 & 4.0 & 2.0 & 4.0 & 2.0
\end{tabular}

\begin{tabular}{lllllllllll}
\hline Mode & 5.0 & 4.0 & 4.0 & 2.0 & 4.0 & 2.0 & 4.0 & 2.0 & 4.0 & 2.0
\end{tabular}

\begin{tabular}{lllllllllll}
\hline Standa & 0.9 & 1.0 & 1.0 & 1.2 & 0.9 & 1.0 & 0.8 & 1.1 & 0.8 & 1.1
\end{tabular}

Deviati

on

\begin{tabular}{lllllllllll}
\hline Kurtosi & 3.1 & 0.0 & -0.7 & -1.2 & 1.7 & -0.9 & 1.8 & -0.6 & 1.0 & -1.5
\end{tabular}

$\mathrm{s}$

$\begin{array}{lllllllllll}\text { Skewn } & -1.8 & -0.9 & -0.4 & 0.1 & -1.3 & 0.2 & -1.2 & 0.4 & -0.9 & 0.1\end{array}$

ess

\begin{tabular}{lllllllllll}
\hline Range & 3.0 & 3.0 & 3.0 & 4.0 & 3.0 & 3.0 & 3.0 & 4.0 & 3.0 & 3.0
\end{tabular}

\begin{tabular}{lllllllllll}
\hline $\begin{array}{l}\text { Minim } \\
\text { um }\end{array}$ & 2.0 & 2.0 & 2.0 & 1.0 & 2.0 & 1.0 & 2.0 & 1.0 & 2.0 & 1.0
\end{tabular}

$\begin{array}{lllllllllll}\text { Maxim } & 5.0 & 5.0 & 5.0 & 5.0 & 5.0 & 4.0 & 5.0 & 5.0 & 5.0 & 4.0\end{array}$

um

\subsection{The Guideline of Project Scope and Size Hypotheses}

From Table 3, it is found that the effect of the guideline of project scope and size (GPS) on the project outcomes are statistically very significant. The sample mean is 4.4 with the median and mode are equal to 5.0. The standard deviation is 0.9 , meaning that the dataset is not much dispersed about the sample mean. The perceptions of this hypothesis are not much deviated. The kurtosis value of 3.1 depicts that the distribution of the dataset is very pointy (leptokurtic). The distribution is found to be highly skewed to the left $(-1.8)$ indicating that the tail is heavy on the left. This is also represented by the values of the sample mean that is less than the values of the median and the mode. Therefore, the distribution is asymmetric and indicating that the distribution is not normal as well. For the effect of the GPS on the development cost (H1b), statistically, the value of the sample mean is 3.96, and the median and mode are equal to 4.0 relatively. From this observation, it tells that the distribution of the dataset is not normally distributed, and the dispersion of the data about the mean is at 1.0 standard deviation. The skewness value of - 0.9 tells that the distribution of the dataset is moderately skewed to the left. The value of kurtosis of 0 (zero) and/or the same value of the sample mean median and mode indicates that the peak of the distribution is not either pointy or flat but mesokurtic. The distribution for the effect of the GPS on the development cost (DC) is slightly normal as compared to the one from the GPS versus the LT. This is happening when there are four respondents disagreed with $\mathrm{H} 1 \mathrm{~b}$ in which they are representing about $20 \%$ of the sample size, this leads to a tiny skewed of the distribution. But still, the GPS gives an idea to the persons involved in an NPD project about the design content, scope, and size of the project. It helps them by giving some insights into the risks and uncertainty of the new product development project so that an early interpretation can be made [27]. Therefore, the GPS is positively associated with both project outcomes. The majority of the respondents agreed that GPS helps in reducing the development lead time and cost for the NPD project.

\subsection{The Mule Car Program}

The hypotheses of $\mathrm{H} 2 \mathrm{a}$ and $\mathrm{H} 2 \mathrm{~b}$ refers to the investigation on the effect of the mule car program (MCP) on the LT and DC respectively. It is found that the effect was moderately significant as $64 \%$ of the respondents agreed that the MCP is positively associated with the LT. Furthermore, the MCP is believed does not have a negative effect on the overall development cost. About $48 \%$ of the respondents disagreed that the MCP is negatively associated with DC as compared to $36 \%$ who are agreed. Meaning that the MCP is used by this low volume car producer as a front-loading concept to achieve its optimum product development performance [28]. The mean value of the sample for $\mathrm{H} 2 \mathrm{a}$ is 3.8. The median and mode are the same which is 4.0. The smaller value of the mean than the value of the median or mode tells that the distribution of the sample is skewed to the left (negative skewness). This is indicated by the negative value of the skewness of - 0.4. However, the skewness value of -0.4 shows that the distribution of the data is fairly symmetrical and the negative value of kurtosis of -0.7 indicates that the data distribution is not normal, and its peak is almost flat (platykurtic). On the other hand, the values of the sample mean, median and mode are 2.8, 3.0, and 2.0 for $\mathrm{H} 2 \mathrm{~b}$, suggesting that the distribution is also not normal, and the dataset dispersion about the mean is equal to 1.2. The value of kurtosis of -1.2 also indicates that the peak of the distribution again is also flat. Again, the skewness of 0.1 for $\mathrm{H} 2 \mathrm{~b}$ is moderately skewed and the positive value tells that it is skewed to the right. As such, the perceptions of $\mathrm{H} 2 \mathrm{a}$ and $\mathrm{H} 2 \mathrm{~b}$ differ from one to the other. The findings show that the MCP is significantly affected the LT but not the DC. The researcher's assumption of the effect of the MCP on DC is, therefore, cannot be accepted. This supports the established theory of the benefits of a well-organized NPD on the development project goal as insisted by numerous authors in their previous studies [29], [30] that the formal NPD is the key determinant to a development project and product success. 
B. Hambali et al., International Journal of Emerging Trends in Engineering Research, 8(10), October 2020, 6873 - 6878

\subsection{The Model Fixed}

The H3a and H3b hypotheses address the effect of the model fixed (MF) on LT and DC respectively. The descriptive statistics show that the effect of the MF on the LT is significant as the mean, mode and median values are equal to 4.0. This also indicates that the distribution is fairly normal and the kurtosis value of 1.7 depicts that the curve is fairly pointy and the skewness of -1.3 the tail of the distribution is highly skewed to the left. The results for H3b, on the other hand, describe that the effect of MF on DC is not significant as the value of the mean, median and mode are $2.5,2.0$, and 2.0 respectively. The kurtosis (-0.9) and the skewness $(0.2)$ values are indicating that that the peak of the distribution is platykurtic and moderately skewed to the right. The "what if" scenario, therefore, is invalid and not significant. The output shows that the theory remains the same, thus the researcher perceived that further investigation might be more interesting, to see the relationship between MF and DC. When referring to the respondents, it is found that MF is not affecting the development cost as MF is an event that occurs for design review.

\subsection{Prototype Testing}

For $\mathrm{H} 4 \mathrm{a}$ and $\mathrm{H} 4 \mathrm{~b}$, the findings show the effect of the F-Proto on the LT and the DC. Based on Table 4.5 the mean, median, and mode values for $\mathrm{H} 4 \mathrm{a}$ are $4.1,4.0$, and 4.0 respectively. It is also found that the dataset is not widely spread out about the mean as the standard deviation is 0.8 . With the value of the kurtosis equal to 1.8 , the distribution is expected to be moderately pointy. The skewness value of -1.2 suggests that the distribution is heavily left-skewed. This is in line with the theory that formal NPD has a positive impact on project goals. On the contrary, the results for $\mathrm{H} 4 \mathrm{~b}$ portrays the mean of 2.6 and the 2.0 for both median and mode. The standard deviation of 1.1 shows the spread of the dataset about the mean. And the negative value of the kurtosis (-0.6) tells that the peak of the distribution is moderately flat, and the tail is slightly skewed to the right as the skewness is equal to 0.4 . This indicates that even though the development of prototypes involves specific budget allocation, this budget is considered as an acceptable budget. Similarly, both hypotheses H5a and H5b are used to see the effect of P-proto on LT and DC. The descriptive results show a comparable pattern as found for the H4a and $\mathrm{H} 4 \mathrm{~b}$. With the mean, median, and mode values of 3.9, 4.0, and 4.0, the standard deviation of 0.8 , kurtosis of 1.0 , and skewness equal to -0.9 the shape of the distribution of H5a resembles the distribution of H4a. For H5b the shape of the distribution is about the same as the one for $\mathrm{H} 4 \mathrm{~b}$. The mean value is equal to 2.8 , the median and mode of the distribution are having the same values of 2.0. The standard deviation of 1.1 tells how dispersed the dataset about the mean. The kurtosis of -1.5 and skewness of 0.1 indicate that the peak is flat, and the tail is skewed to the right and almost symmetrical. The prototype testing is one of the crucial NPD practices to this low volume car producer, it helps to reduce the doubt and risks that are arising especially from the product-process complexity, and technological uncertainty [31], [32]. The prototypes are used for proof-of-concept and the functional test using the F-proto and P-proto that is produced via, for example, additive manufacturing, and soft tooling.

\section{CONCLUSION}

A well-defined NPD process is crucial for product manufacturers, including vehicles in the automotive industry. From this research, the low volume Malaysian car producer is found to have its specific product development practices that help to improve the product development performance. The formal NPD process is also important to the car producer and has been used to manage project characteristics. Regardless of what are the development activities in the NPD phases, they are executed to enhance and improve the development process and so that the project goals can be achieved at the optimum target. For future research, studying new product development of a product family or product portfolio will be very interesting, especially for a small player like this Malaysian car producer. Since global car manufacturers, including large OEMs such as Volkswagen and Toyota as well as relatively small ones such as BMW, Subaru, Mazda, have long addressed the development of multiple products systematically. Given that this low volume car producer will have to offer a certain level of product variety under limited production volume, platform or parts-sharing would be a crucial strategy. Expanding the scope of study from a single project level to a multi-project level will be beneficial for small manufacturers.

\section{ACKNOWLEDGEMENT}

This research was conducted with support from the Malaysian car producer, and sponsored by Universiti Teknikal Malaysia, Melaka (UTeM).

\section{REFERENCES}

[1] S. Ahmad, D. N. Mallick, and R. G. Schroeder, "New product development: Impact of project characteristics and development practices on performance," J. Prod. Innov. Manag., vol. 30, no. 2, pp. 331-348, 2013.

[2] M. Israr and A. Gangele, "A Quality Function Deployment Methodology for Product Development," Int. J. Emerg. Trends Eng. Res., vol. 2, no. 11, pp. 52-63, 2014.

[3] K. T. Ulrich and S. D. Eppinger, Product Design and Development: Fifth Edition. NY, Mc Graw Hill, 2012, ch.2.

[4] M. Graner and M. Mißler-Behr, "Key determinants of the successful adoption of new product development methods," Eur. J. Innov. Manag., vol. 16, no. 3, pp. 301-316, 2013. 
B. Hambali et al., International Journal of Emerging Trends in Engineering Research, 8(10), October 2020,6873 - 6878

[5] M. V. Tatikonda and S. R. Rosenthal, "Technology novelty, project complexity, and product development project execution success: A deeper look at task uncertainty in product innovation," IEEE Trans. Eng. Manag., vol. 47, no. 1, pp. 74-87, 2000.

[6] H. Boejang, H. Ariff, M. Z. Hassan, and S. Esa, 'Dealing with project characteristics through concurrent product development by Malaysian car producer,' Int. J. Emerg. Trends Eng. Res., 2019.

[7] M. Iansiti et al., Technology integration: Managing technological evolution in a complex environment. Research Policy, vol. 24, pp. 521-542., 1995.

[8] C. Nakata and K. Sivakumar, "National Culture and New Product Development: An Integrative Review," J. Mark., 1996.

[9] H. Boejang, A. Hambali, M. Z. Hassan, S. Esa, and M. Rauterberg, "An exploration on new product development process of Malaysian small-sized automaker," J. Adv. Manuf. Technol., vol. 11, no. 2, pp. 33-46, 2017.

[10] R. Beaume, R. Maniak, and C. Midler, "Crossing innovation and product projects management: $\mathrm{A}$ comparative analysis in the automotive industry," Int. J. Proj. Manag., 2009.

[11] D. W. Unger and S. D. Eppinger, "Comparing Product Development Processes and Managing Risk," Int. J. Prod. Dev., vol. 8, no. 4, pp. 382-402, 2009.

[12] K. B. Kahn, S. E. Kay, R. J. Slotegraaf, and S. Uban, PDMA Handbook of New Product Development (3rd Edition).pdf. 2013

[13] T. Yan and S. M. Wagner, "Do what and with whom? value creation and appropriation in inter-organizational new product development projects,' Int. J. Prod. Econ., 2017.

[14] S. C. Wheelwright and K. Clark, "Competing through development capability in a manufacturing-based organization," Bus. Horiz., vol. 35, no. 4, pp. 29-43, 1992.

[15] P. Spieth and V. Joachim, "Reducing front end uncertainties: How organisational characteristics influence the intensity of front end analysis," Technol. Forecast. Soc. Change, vol. 123, no. July, pp. 108-119, 2017.

[16] P. M. Swamidass, "Book Review: Competing Against Time: How Time-Based Competition is Reshaping Global Markets," J. Manage., 1991.

[17] K. M. Eisenhardt and B. N. Tabrizi, "Accelerating Adaptive Processes: Product Innovation in the Global Computer Industry," Adm. Sci. Q., vol. 40, no. 1, p. 84, 2006.

[18] J. P. Kruth, "Material Incress Manufacturing by Rapid Prototyping Techniques," CIRP Ann. Manuf. Technol., 1991.

[19] B. Prasad, "Book Reviews : Stereolithography and
Other RP\&M Technologies from Rapid Prototyping to Rapid Tooling, published by Society of Manufacturing Engineers in cooperation with the Rapid Prototyping Association of SME, De," Concurr. Eng., 1996.

[20] A. Awwad and D. M. N. Akroush, "New product development performance success measures: an exploratory research," EuroMed J. Bus., vol. 11, no. 1, pp. 2-29, 2016.

[21] H. Boejang, M. Z. Hassan, T. Mokudai, H. Ariff, and S. Esa, "Measuring effectiveness and efficiency of a new product development project using performance matrix-The PROTON case," IOP Conf. Ser. Mater. Sci. Eng., vol. 627, no. 1, pp. 0-7, 2019.

[22] J. Mu, "Marketing capability, organizational adaptation and new product development performance," Ind. Mark. Manag., vol. 49, pp. 151-166, 2015.

[23] K. A. Fantazy and M. Salem, "The value of strategy and flexibility in new product development: The impact on performance," J. Enterp. Inf. Manag., 2016.

[24] K. B. Clark and T. Fujimoto, "Product Development Performance: Strategy, Organization, and Management in the World Auto Industry." p. 409, 1991.

[25] M. Fleischer and J. K. Liker, "The hidden professionals: Product designer and their impact on design quality," IEEE Trans. Eng. Manag., vol. 39, no. 3, pp. 254-264, 1992.

[26] C. B. Thompson, "Descriptive Data Analysis," Air Med. J., vol. 28, no. 2, pp. 56-59, 2009.

[27] Q. Lu and L. Wood, "The refinement of design for manufacture: Inclusion of process design," Int. J. Oper. Prod. Manag., 2006.

[28] S. Thomke and T. Fujimoto, "Effect of 'front-loading' problem-solving on product development performance," J. Prod. Innov. Manag., vol. 17, no. 2, pp. 128-142, 2000.

[29] G. Barczak and K. B. Kahn, "Identifying new product development best practice," Bus. Horiz., vol. 55, no. 3, pp. 293-305, 2012.

[30] V. Mahajan and J. Wind, "New product models: Practice, shortcomings and desired improvements," J. Prod. Innov. Manag., 1992.

[31] C. W. Elverum, T. Welo, and S. Tronvoll, "Prototyping in New Product Development: Strategy Considerations," in Procedia CIRP, 2016.

[32] R. Jamieson and J. Hammond, "Rapid wind tunnel prototype using stereolithography and equivalent technologies," in IEE Colloquium (Digest), 1994. 